\title{
Anharmonic vibrations of the dicarbon antisite defect in $4 \mathrm{H}-\mathrm{SiC}$
}

\section{AUTHOR(S):}

Yan, F.; Devaty, R. P.; Choyke, W. J.; Gali, A.; Kimoto, T.; Ohshima, T.; Pensl, G.

\section{CITATION:}

Yan, F.... [et al]. Anharmonic vibrations of the dicarbon antisite defect in 4H-SiC. APPLIED PHYSICS LETTERS 2012, 100(13): 132107.

\section{ISSUE DATE:}

2012-03

URL:

http://hdl.handle.net/2433/160623

\section{RIGHT:}

Copyright 2012 American Institute of Physics. This article may be downloaded for personal use only. Any other use requires prior permission of the author and the American Institute of Physics. The following article appeared in APPLIED PHYSICS LETTERS 100, 132107 (2012) and may be found at http://link.aip.org/link/?apl/100/132107 


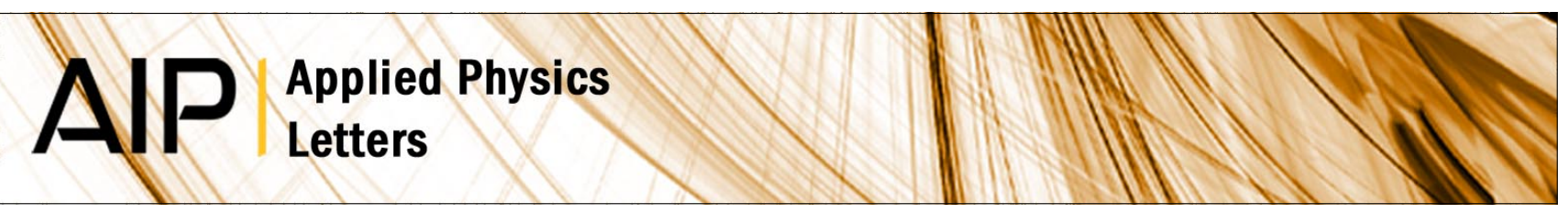

\section{Anharmonic vibrations of the dicarbon antisite defect in $4 \mathrm{H}-\mathrm{SiC}$}

F. Yan, R. P. Devaty, W. J. Choyke, A. Gali, T. Kimoto et al.

Citation: Appl. Phys. Lett. 100, 132107 (2012); doi: 10.1063/1.3699269

View online: http://dx.doi.org/10.1063/1.3699269

View Table of Contents: http://apl.aip.org/resource/1/APPLAB/v100/i13

Published by the American Institute of Physics.

\section{Related Articles}

Quantum Monte Carlo study of high-pressure cubic TiO2

Appl. Phys. Lett. 100, 261902 (2012)

Isotope effect in the superconducting high-pressure simple cubic phase of calcium from first principles J. Appl. Phys. 111, 112604 (2012)

Vibrational properties of alkyl monolayers on $\mathrm{Si}(111)$ surfaces: Predictions from ab-initio calculations Appl. Phys. Lett. 100, 071605 (2012)

Anisotropic response of nanosized bismuth films upon femtosecond laser excitation monitored by ultrafast electron diffraction

Appl. Phys. Lett. 99, 161905 (2011)

Characteristic non-Debye heat capacity formula applied to $\mathrm{GaN}$ and $\mathrm{ZnO}$

J. Appl. Phys. 110, 043530 (2011)

\section{Additional information on Appl. Phys. Lett.}

Journal Homepage: http://apl.aip.org/

Journal Information: http://apl.aip.org/about/about_the_journal

Top downloads: http://apl.aip.org/features/most_downloaded

Information for Authors: http://apl.aip.org/authors

\section{ADVERTISEMENT}

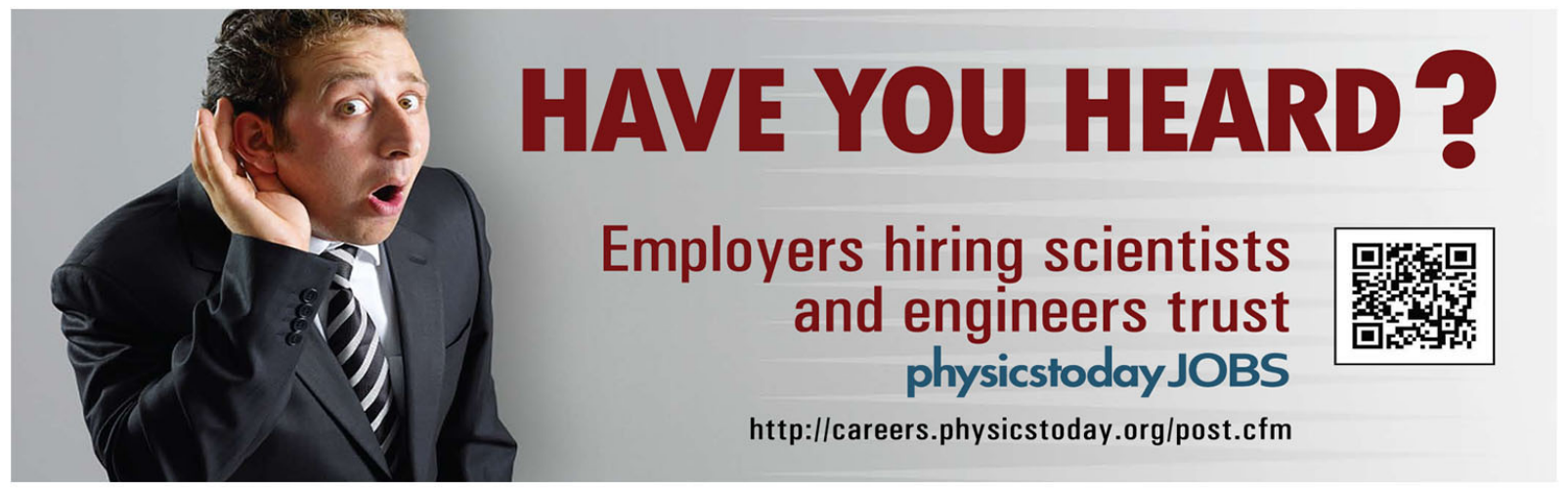




\title{
Anharmonic vibrations of the dicarbon antisite defect in $4 \mathrm{H}-\mathrm{SiC}$
}

\author{
F. Yan, ${ }^{1, a)}$ R. P. Devaty, ${ }^{1}$ W. J. Choyke,${ }^{1}$ A. Gali, ${ }^{2}$ T. Kimoto, ${ }^{3}$ T. Ohshima,${ }^{4}$ and G. Pens ${ }^{5}$ \\ ${ }^{1}$ Department of Physics and Astronomy, University of Pittsburgh, Pittsburgh, Pennsylvania 15260, USA \\ ${ }^{2}$ Research Institute for Solid State Physics and Optics, Hungarian Academy of Sciences, P.O. Box 49, \\ H-1525 Budapest, Hungary \\ ${ }^{3}$ Department of Electronic Science and Engineering, Kyoto University, Katsura, Nishikyo, \\ Kyoto 615-8510, Japan \\ ${ }^{4}$ Japan Atomic Energy Agency, 1233 Watanuki, Takasaki, Gunma 370-1292, Japan \\ ${ }^{5}$ Lehrstuhl für Angewandte Physik, Universität Erlangen-Nürnberg, Staudstr. 7/A3 Erlangen, Germany
}

(Received 13 December 2011; accepted 15 March 2012; published online 29 March 2012)

\begin{abstract}
Dicarbon antisite defects were created by either electron irradiation or ion implantation into 4H-SiC. The no-phonon lines from the dicarbon antisite defect center were observed with their phonon replicas. The stretch frequencies of the defect were observed up to the fifth harmonic. The Morse potential model accounts for the anharmonicity quite well and gives a very good prediction of the vibration energies up to the fifth harmonic with an error of less than $1 \%$. First principles calculations show that the model of a dicarbon antisite defect along with its four nearest neighboring carbon atoms can explain the observed anharmonicity. (C) 2012 American Institute of Physics. [http://dx.doi.org/10.1063/1.3699269]
\end{abstract}

As a wide bandgap semiconductor, $\mathrm{SiC}$ has attracted a lot of research interest in recent decades. It has high electron mobility, high breakdown electric field, and high thermal conductivity. All these make it suitable for electronic use under high temperature, high frequency, and high power conditions. Different impurities and defects in SiC have been studied for decades. Recently, Steeds et al. reported a triplet of no phonon lines and their vibrational replicas in $4 \mathrm{H}-\mathrm{SiC}$ after electron irradiation. ${ }^{1}$ By comparing the experimental results to the published results of $a b$ initio local density approximation (LDA) calculations by two groups, ${ }^{2,3}$ the authors conclude that the triplet lines are associated with dicarbon antisite defects in $4 \mathrm{H}-\mathrm{SiC}$. In the previous work from our group, ${ }^{4}$ we reported the no-phonon and phonon replica lines and issues associated with the dicarbon antisite defect by studying the creation and annealing behavior at different temperatures.

In this letter, we report that (i) the dicarbon antisite phonon replicas up to the fifth harmonic have been observed by low temperature photoluminescence (LTPL), (ii) the Morse potential model accounts for the observed anharmonicity, and (iii) the potential energy surface for the stretch vibration calculated from first principles is surprisingly well described by the Morse potential and, by making an appropriate choice for the value of the effective reduced mass, the Morse potential obtained from a fit to the data agrees very well with the calculated potential.

All the samples used in this study were very carefully characterized $15-20 \mu \mathrm{m}$ thick $4 \mathrm{H}-\mathrm{SiC}$ epitaxial layers. ${ }^{5}$ Some were intentionally n-type or p-type doped (doping: $2-4 \times 10^{15} \mathrm{~cm}^{-3}$ ), others were non-intentionally doped, and the doping was not measured. $170 \mathrm{keV}$ and $1 \mathrm{MeV}$ electron irradiations were carried out at fluences of $10^{15} \mathrm{~cm}^{-2}$ to $5 \times 10^{16} \mathrm{~cm}^{-2}$. The samples were put on a water-cooled plate during electron irradiation to avoid heating. The $\mathrm{H}^{+}$and

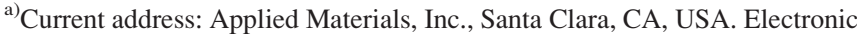
mail: feiyan@gmail.com.
}

${ }^{4} \mathrm{He}^{+}$bombardments were at the $5 \times 10^{10} \mathrm{~cm}^{-2}$ fluence level. The samples were annealed in $\mathrm{Ar}$ for $30 \mathrm{~min}$ at temperatures between $700{ }^{\circ} \mathrm{C}$ and $1700^{\circ} \mathrm{C}$ with $100{ }^{\circ} \mathrm{C}$ intervals. Temperatures were raised directly from room temperature to the desired temperature for every individual sample. A particular sample was annealed only once, so a large number of identical samples were used for this study. The LTPL measurements were carried out at $2 \mathrm{~K}$ using an immersion type liquid He cryostat. A frequency doubled argon ion (FreD) laser at $244 \mathrm{~nm}$ wavelength at an excitation power of $40 \mathrm{~mW}$ was used as the excitation source. The luminescence was dispersed in an asymmetric Czerny-Turner spectrometer and collected with a liquid nitrogen cooled charge-coupled device (CCD) array with approximately $0.1 \mathrm{meV}$ resolution.

In Fig. 1 and Table I, we show the phonon replicas observed for the triplet no-phonon lines $\mathrm{a}_{0}, \mathrm{~b}_{0}$, and $\mathrm{c}_{0}$, where the subscript 0 indicates a no-phonon line, and $\mathrm{H}_{\mathrm{n}}^{\mathrm{a}}$ indicates the nth harmonic of the high-energy local vibrational modes of $\mathrm{a}_{0}$. The slit size was $100 \mu \mathrm{m}$. In Table $\mathrm{I}, \Delta \mathrm{E}^{\mathrm{ph}}{ }_{3-2}$, for example, is the additional vibrational energy (third vibrational quantum) contributing to the third replica, relative to the second replica. The $\mathrm{a}_{0}, \mathrm{~b}_{0}, \mathrm{c}_{0}$ lines have first order phonon replicas of about 132 and $180 \mathrm{meV}$. However, for the second harmonic replicas a combination of the 132 and $180 \mathrm{meV}$ modes is also observed. Especially note-worthy is the observation of five harmonics for the $a_{0}$ line with decreasing energy, indicating anharmonicity. The theoretical calculations show that the high energy local vibrational mode can be interpreted as due to the stretching vibration of the $\mathrm{C}-\mathrm{C}$ dumbbell in the dicarbon antisite $\left(\mathrm{C}_{2}\right)_{\mathrm{Si}}$. Therefore, we can treat the $\mathrm{C}-\mathrm{C}$ dumbbell as an anharmonic diatomic configuration using the Morse potential, ${ }^{6}$ assuming that the interaction with the rest of the lattice can be built into the parameters. For a Morse potential, the energy spacing between two consecutive energy levels decreases with increasing vibrational quantum number. The difference between adjacent energy spacings is a constant. Using the first two energy spacings observed in Fig. 1, we calculated the two 

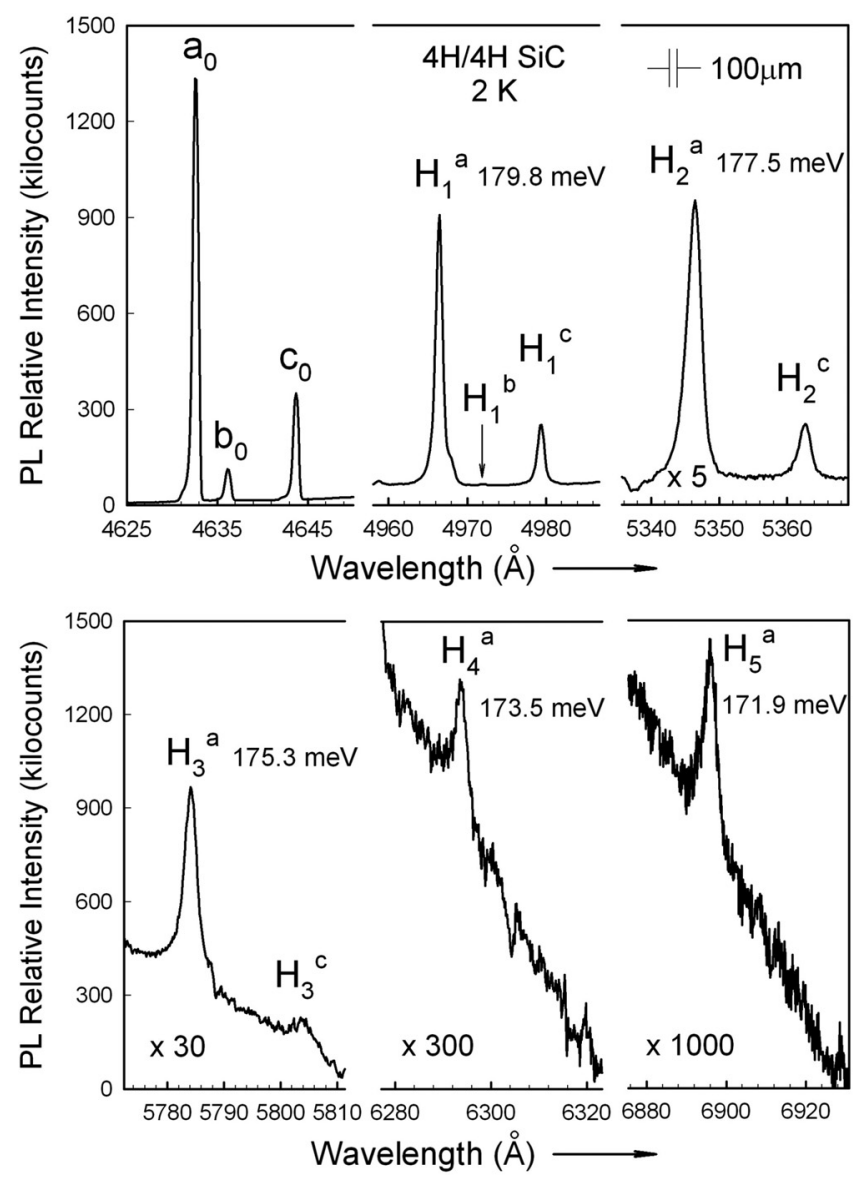

FIG. 1. Triplet no-phonon lines $\mathrm{a}_{0}, \mathrm{~b}_{0}, \mathrm{c}_{0}$ and the high-energy local vibrational modes of $\mathrm{a}_{0}$ up to the fifth harmonic.

parameters associated with a Morse potential fit. Then we calculated the energies of the third, fourth, and fifth order vibrational modes. The results from the Morse potential predictions and the experimental results from LTPL measurements are listed in Table II. We can see that they agree well within an error of less than $1.3 \mathrm{meV}$ up to the fifth harmonic, which is just $0.8 \%$ in error.

The proposed model of the PL centers is the dicarbon antisite defect. ${ }^{1}$ For the first principles calculations, we focus our investigation particularly on the high-spin $(S=1)$ configuration at the hexagonal site in $4 \mathrm{H}-\mathrm{SiC}$. This defect is modeled in a large 576-atom supercell using the $\Gamma$-point for $\mathrm{K}$-point sampling that ensures both the convergent charge density and the monitoring of the (quasi) degenerate defect
TABLE II. A comparison of experiment and Morse potential predictions for the harmonic energies up to the fifth order of the dicarbon antisite C-C dumbbell vibrations in $4 \mathrm{H}-\mathrm{SiC}$.

\begin{tabular}{lccccc}
\hline \hline Triplet line a & $\begin{array}{c}\Delta E_{10} \\
(\mathrm{meV})\end{array}$ & $\begin{array}{c}\Delta E_{21} \\
(\mathrm{meV})\end{array}$ & $\begin{array}{c}\Delta E_{32} \\
(\mathrm{meV})\end{array}$ & $\begin{array}{c}\Delta E_{43} \\
(\mathrm{meV})\end{array}$ & $\begin{array}{c}\Delta E_{54} \\
(\mathrm{meV})\end{array}$ \\
\hline Experiment & 179.8 & 177.5 & 175.3 & 173.5 & 171.9 \\
Morse potential Prediction & - & - & 175.2 & 172.9 & 170.6 \\
\hline \hline
\end{tabular}

levels at the same time. We applied a plane wave cutoff of $420 \mathrm{eV}$ with the projector augmented wave (PAW) method and density functional theory within the LDA(Ref. 7) to calculate the total energies and forces. We utilized the VASP code for the calculations. ${ }^{8}$ We optimized the full geometry until the forces were below the given threshold. We note that the symmetry of the defect is $\mathrm{C}_{1 \mathrm{~h}}$ in $4 \mathrm{H}-\mathrm{SiC}$, but the local symmetry resembles the $\mathrm{D}_{2 \mathrm{~d}}$ symmetry in a $3 \mathrm{C}-\mathrm{SiC}$ crystal. The vibrational modes within the quasi-harmonic approximation were calculated as the numerical derivative of the forces. We applied a defect-molecule model in the calculation of vibrations: either (i) $\mathrm{C} 1$ and $\mathrm{C} 2$ atoms or (ii) $\mathrm{C} 1$ to $\mathrm{C} 6$ atoms were allowed to vibrate (see Fig. 2). The calculated stretch mode energy in the case (i) was about $172 \mathrm{meV}$, which slightly increased to $174 \mathrm{meV}$ in the case (ii). In the case (ii), we obtained $136 \mathrm{meV}$ for the symmetrically allowed bending mode that can be tentatively compared to the experimental value of $132 \mathrm{meV}$. Based on our previous results, we believe that the main reason for the discrepancy between the calculated $(174 \mathrm{meV})$ and measured $(\sim 180 \mathrm{meV})$ stretch modes is due to the limitation on the number of atoms that were allowed to vibrate and that the LDA potential energy surface (PES) is sufficiently appropriate. In this study, we aim to understand the anharmonicity of the stretch mode. We found for both cases (i) and (ii) that the normal coordinates of the stretch mode show the motion of $\mathrm{C} 1$ and $\mathrm{C} 2$ atoms along their bond. This enables a simplification of the description of the stretch mode to a onedimensional model where only $\mathrm{C} 1$ and $\mathrm{C} 2$ atoms are moving symmetrically with respect to their bond center by compressing or expanding the bonding distance between them. We mapped the PES at 17 points where the maximum compression (expansion) of the bond was about $0.24(0.36) \AA$. We obtained a very accurate fit of a Morse potential to the calculated first principles data despite the fact that the Morse potential contains only two parameters. A comparison of the

TABLE I. "Dumbbell" center triplet no-phonon lines with phonon replicas. $\Delta \mathrm{E}^{\mathrm{ph}}{ }_{1-0}$ is the additional vibrational energy (first vibrational quantum) contributing to the first replica relative to the no-phonon line. $\Delta \mathrm{E}^{\mathrm{ph}}{ }_{2-1}$ is the additional vibrational energy (second vibrational quantum) contributing to the second replica relative to the first replica and similarly for $\Delta \mathrm{E}^{\mathrm{ph}}{ }_{3-2}, \Delta \mathrm{E}^{\mathrm{ph}}{ }_{4-3}$, and $\Delta \mathrm{E}^{\mathrm{ph}}{ }_{5-4}$.

\begin{tabular}{lcccc}
\hline \hline No-phonon lines $(\AA)$ & $\Delta \mathrm{E}^{\mathrm{ph}}{ }_{1-0}(\mathrm{meV})$ & $\Delta \mathrm{E}^{\mathrm{ph}}{ }_{2-1}(\mathrm{meV})$ & $\Delta \mathrm{E}^{\mathrm{ph}}{ }_{3-2}(\mathrm{meV})$ & $\Delta \mathrm{E}^{\mathrm{ph}}{ }_{4-3}(\mathrm{meV})$ \\
\hline $\mathrm{a}_{0} 4632.46$ & 179.8 & 177.5 & 175.3 & 173.5 \\
$\mathrm{~b}_{0} 4635.79$ & 180.7 & & & \\
$\mathrm{c}_{0} 4643.51$ & 180.0 & 177.9 & 175.5 & \\
$\mathrm{a}_{0} 4632.46$ & 132.4 & 132.5 & & \\
$\mathrm{~b}_{0} 4635.79$ & 132.3 & & & \\
$\mathrm{c}_{0} 4643.51$ & 131.4 & 131.3 & 171.9 \\
$\mathrm{a}_{0} 4632.46$ & 132.4 & 179.9 & 177.6 & 175.0 \\
$\mathrm{c}_{0} 4643.51$ & 131.4 & 180.0 & 178.2 & 175.2 \\
\hline \hline
\end{tabular}




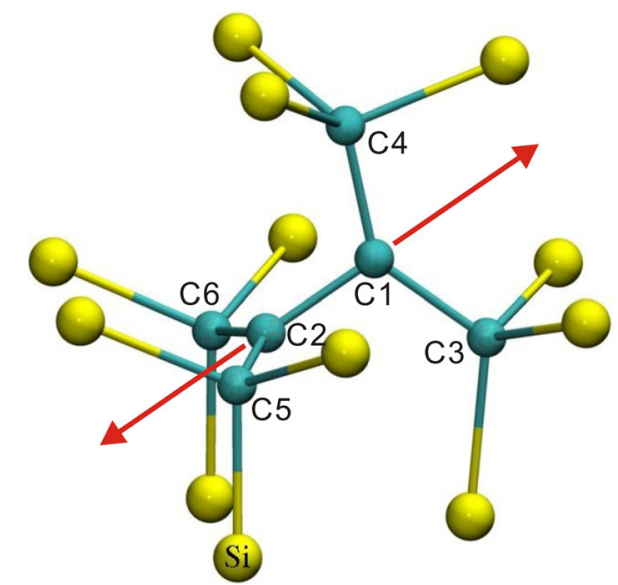

FIG. 2. Dicarbon antisite defect at the hexagonal site in 4H-SiC. Carbon atoms $\mathrm{C} 1$ and $\mathrm{C} 2$ form the "dumbbell" mentioned in the text. The carbon atoms are labeled by numbers. The arrows indicate the motion of atoms $\mathrm{C} 1$ and $\mathrm{C} 2$ in the stretch vibration mode.

Morse potential fit and the first principles calculation is shown in Fig. 3. This one-dimensional Morse potential can be applied in the one-dimensional Schrödinger equation where the kinetic energy contains the effective reduced mass $(\mu)$ of the vibrating system. If the $\mathrm{C} 1$ and $\mathrm{C} 2$ atoms did not connect to the rest of the $\mathrm{SiC}$ crystal then $\mu=m_{\mathrm{C}} / 2$, where $m_{\mathrm{C}}$ is the mass of the ${ }^{12} \mathrm{C}$ isotope. However, $\mu$ will be reduced due to the fact that $\mathrm{C} 1$ and $\mathrm{C} 2$ atoms are bound to the rest of $\mathrm{SiC}$ crystal, so $\mu=\chi m_{\mathrm{C}} / 2$, where $\chi<1$. We used $\mu$ as a parameter to fit the first transition to the experimental value of $179.8 \mathrm{meV}$. For this choice, we found that reduced mass $\mu$ value of 9983.939635 a.u. would fit the data and $\chi \approx 0.9$, which is physically reasonable.

In summary, we have been able to obtain a surprisingly sharp and detailed spectrum of the vibrational modes of the dicarbon antisite defect in $4 \mathrm{H}-\mathrm{SiC}$ up to the fifth harmonic. It is possible to obtain a Morse potential fit to our data which, using positions of the first two harmonics, predicts harmonics 3,4 , and 5 to an accuracy of better than $99 \%$. Fortunately, first principles calculations of vibrational modes are quite

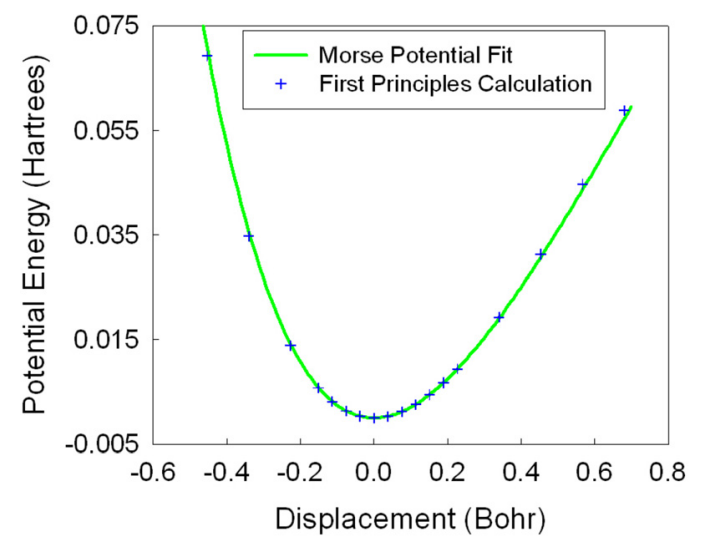

FIG. 3. Plots of both the Morse potential fit and the potential obtained from first principles calculation.

accurate and reliable, and we have used such calculations to obtain theoretical values of the mode frequencies for our dicarbon antisite. The agreement between theory and experiment is very good, giving us great confidence in the assignment of our observed defect in $4 \mathrm{H}-\mathrm{SiC}$ to the dicarbon antisite, one of the few defects in $\mathrm{SiC}$ which is now fairly well understood.

The University of Pittsburgh group thanks the II-VI Foundation for the support of this research.

${ }^{1}$ J. W. Steeds, W. Sullivan, S. A. Furkert, G. A. Evans, and P. J. Wellmann, Phys. Rev. B 77(19), 195203 (2008).

${ }^{2}$ A. Gali, P. Deák, P. Ordejón, N. T. Son, E. Janzén, and W. J. Choyke, Phys. Rev. B 68(12), 125201 (2003).

${ }^{3}$ M. Bockstedte, A. Mattausch, and O. Pankratov, Phys. Rev. B 68(20), 205201 (2003)

${ }^{4}$ F. Yan, R. P. Devaty, W. J. Choyke, T. Kimoto, T. Ohshima, G. Pensl, and A. Gali, Mater. Sci. Forum 645-648, 411 (2010).

${ }^{5}$ T. Kimoto, A. Itoh, H. Matsunami, S. Sridhara, L. L. Clemen, R. P. Devaty, W. J. Choyke, T. Dalibor, C. Peppermüller, and G. Pensl, Appl. Phys. Lett. 67(19), 2833 (1995).

${ }^{6}$ P. M. Morse, Phys. Rev. 34(1), 57 (1929).

${ }^{7}$ J. P. Perdew and A. Zunger, Phys. Rev. B 23(10), 5048 (1981).

${ }^{8}$ G. Kresse and J. Furthmüller, Phys. Rev. B 54(16), 11169 (1996). 